\title{
Leguminosae na APA do Cariri, Estado da Paraíba, Brasil
}

\author{
Paulo Sérgio Monteiro Ferreira ${ }^{1}$, Dilma Maria de Brito Melo Trovão ${ }^{1}$ e José Iranildo Miranda de Melo ${ }^{1,2}$
}

Recebido: 7.01.2015; aceito: 24.04.2015

\begin{abstract}
Leguminosae at APA do Cariri, Paraíba State, Brazil). Leguminosae Juss. is a largely distributed family, being dominant in several dry ecosystems, such as the Caatinga woodlands. This work deals with the taxonomic survey of Leguminosae at the Cariri Environmental Protected Area, semiarid of the Paraíba State, Northeast Brazil. Thirty-one species were found in the total, $22.6 \%$ of which accredited as endemic to the Caatinga. The most taxonomically diverse genus was Senna, with five species. Seven species were recorded for the first time to the Paraíba State (C. belemii var. belemii, D. violacea, I. blanchetiana, P. microphilla, V. halophila, Z. echinocarpa, and Z. myriadena). The shrubby habit was the most representative, with $45.2 \%$ of the total of registered species, followed by herbaceous and tree habits, with 22.6 and $16.1 \%$, respectively. Vines and lianas totalized 9.7 and $6.5 \%$ of the species, respectively. This treatment includes keys for separation into subfamilies and their species, a list of examined materials, data on geographic distribution, and illustrations. Keywords: Caatinga vegetation, Environmental Protection Area, Fabaceae, taxonomy
\end{abstract}

RESUMO - (Leguminosae na APA do Cariri, Estado da Paraíba, Brasil). Leguminosae Juss. é uma família amplamente distribuída, sendo dominante em alguns ecossistemas, como na Caatinga. Este trabalho trata do levantamento taxonômico de Leguminosae na Área de Proteção Ambiental (APA) do Cariri, semiárido paraibano, nordeste do Brasil. Foram encontradas ao todo 31 espécies, $22,6 \%$ das quais acreditadas como endêmicas da Caatinga. $\mathrm{O}$ gênero mais diverso taxonomicamente foi Senna, com cinco espécies. Sete espécies foram referidas pela primeira vez para o Estado da Paraíba (C. belemii var. belemii, D. violacea, I. blanchetiana, P. microphilla, V. halophila, Z. echinocarpa e Z. myriadena). O hábito arbustivo foi o mais representativo, com 45,2\% do total de espécies registradas, seguido pelos hábitos herbáceo e arbóreo, com 22,6 e 16,1\% respectivamente. As trepadeiras e lianas perfizeram respectivamente 9,7 e 6,5\% das espécies. O tratamento taxonômico inclui chaves de identificação para subfamílias e respectivas espécies, dados de distribuição geográfica e ilustrações.

Palavras-chave: Área de Proteção Ambiental, Caatinga, Fabaceae, taxonomia

\section{Introdução}

Leguminosae Juss. pertence à Ordem Fabales (APG III 2009), e está classicamente dividida em três subfamílias: Caesalpinioideae, Mimosoideae e Papilionoideae, sendo Caesalpinioideae um grupo parafilético da qual se ramificaram as outras duas subfamílias (LPWG 2013). Apresenta ampla distribuição mundial, de modo que seus representantes podem ser encontrados em todos os ambientes, constituindo-se na terceira maior família de plantas, com cerca de 750 gêneros e 19.500 espécies (LPWG 2013).

A importância ecológica da família é explicitada ao observar-se que suas espécies constituem as dominantes em alguns ecossistemas. Por exemplo, espécies de Acacia (Simpson 2006) em áreas do Miombo africano (Goedert et al. 2008) e as regiões semiáridas da Austrália (Ariati et al. 2006), além de a própria Caatinga ser um ecossistema onde essa família é dominante, com diversas espécies de Senna e Mimosa sendo frequentes (Queiroz et al. 2006). Adicionalmente, grande parte da importância ecológica das leguminosas pode ser explicada pelos serviços ecossistêmicos realizados por essas plantas, pelo fato de muitas delas apresentarem em suas raízes associações simbióticas com microrganismos fixadores de nitrogênio (Gurevitch et al. 2009, LPWG 2013).

Economicamente as leguminosas se sobressaem como a principal fonte vegetal de proteína (Lewis 1987) com destaque à alimentação humana e animal

1. Universidade Estadual da Paraíba, Centro de Ciências Biológicas e da Saúde, Departamento de Biologia, CEP 58429-500 Campina Grande, PB, Brasil

2. Autor para correspondência: tournefort@gmail.com 
sendo também utilizadas como plantas aromatizantes, forrageiras, na adubação verde como rotação de culturas, produção de óleos, de madeira, gomas, corantes e inseticidas (Simpson 2006).

No Brasil ocorrem 222 gêneros e 2.807 espécies de leguminosas, dos quais 168 gêneros e 1.083 espécies dispersam-se na região Nordeste (Lima et al. 2015). $\mathrm{Na}$ vegetação de Caatinga foram registrados 127 gêneros e 593 espécies, das quais 149 são endêmicas (Lima et al. 2015), e de acordo com Barbosa et al. (2007) na microrregião do Cariri Paraibano estão documentadas 71 espécies pertencentes a 34 gêneros, esperando-se uma riqueza ainda maior a partir da realização de novos levantamentos.

O ecossistema Caatinga apresenta uma ampla variedade de paisagens e significativa riqueza biológica, contrariando ideias anteriores, que defendiam que sua fisionomia se dava em decorrência da degradação de formações vegetais mais exuberantes, como a Mata Atlântica ou a Floresta Amazônica (Alves, 2007, Abílio 2010). Apesar disto, menos de $2 \%$ da área da Caatinga remanescente está protegida por Unidades de Conservação, mostrando assim, a grande necessidade de conservação dos seus sistemas naturais, bem como da ampliação do conhecimento científico direcionado a esse ecossistema (Cortez et al. 2007, Abílio 2010).

Este estudo apresenta o levantamento taxonômico de Leguminosae na Área de Proteção Ambiental (APA) do Cariri, Estado da Paraíba, Nordeste do Brasil, visando ampliar o conhecimento sobre a diversidade taxonômica e a distribuição da família no semiárido brasileiro, especialmente na Paraíba.

\section{Material e métodos}

Caracterização da Área - A região paraibana denominada Cariri situa-se na superfície do Planalto da Borborema, formando uma saliência voltada para o sudoeste deste Planalto. A região é composta por 29 municípios e ocupa uma área de $11.233 \mathrm{~km}^{2}$. Seus limites passam ao Sul do eixo rodoviário da BR-230 e suas vias de acesso se situam entre Queimadas e Boqueirão, a Leste, Soledade ao Norte, e o vale do rio Farinha a Noroeste. O clima da região é semiárido acentuado, forma uma diagonal Nordeste-Sudoeste (NE-SW), também conhecida como diagonal da seca (Alves 2009), com precipitações médias anuais inferiores a $400 \mathrm{~mm}$ (Cohen \& Duqué 2001) e temperatura média anual de $26{ }^{\circ} \mathrm{C}$ (Barbosa et al. 2007).

A Área de Proteção Ambiental (APA) do Cariri foi criada pelo decreto $\mathrm{N}^{\mathrm{o}}$. 25. 083 , de 08 de junho de 2004, com o intuito de proteger o meio físico, biológico e social dos arredores de um maciço rochoso, com aproximadamente $16 \mathrm{~km}$ de comprimento e $2 \mathrm{~km}$ de largura (figuras 1, 2 a). O território da APA é de 18.560 ha, localizado entre os municípios de Boa Vista, Cabaceiras e São João do Cariri, delimitado por segmentos de reta, denominados de vértices V1 a V6, e por limites naturais constituídos por trechos do Rio Taperoá e pelo Riacho Gangorra; também pertence à área da APA, uma faixa contínua de $1.000 \mathrm{~m}$ contada a partir do leito destes cursos d'água, no sentido exterior das Áreas de Preservação Ambiental (Fialho et al. 2010). A Caatinga dessa área é composta por uma fitofisionomia predominantemente arbustivoarbórea, apresentando trechos de solo exposto e segundo Andrade-Lima (1981), está sob o domínio de Caesalpinia-Aspidosperma.

Estudos de campo e laboratório - Os trabalhos de campo consistiram de coletas, realizadas através de caminhadas sistemáticas bimestrais, entre agosto/2011 e julho/2012. Durante as incursões foram coletados espécimes férteis (com flores e/ou frutos) de todas as espécies de Leguminosae encontradas na área de estudo. Imagens digitalizadas foram obtidas de estruturas florais e dos frutos, e parte dessas estruturas estocadas em meio líquido (álcool a $70 \%$ ou FAA). Os exemplares foram prensados e encaminhados para herborização em estufa a $50{ }^{\circ} \mathrm{C}$ por $48-72$ horas no Laboratório de Botânica, Departamento de Biologia, da Universidade Estadual da Paraíba (UEPB), Campus I, e as coleções obtidas foram incorporadas ao Herbário Manuel de Arruda Câmara (ACAM) e ao Herbário Jayme Coelho de Moraes (EAN), Universidade Federal da Paraíba, Campus II.

As análises morfo-taxonômicas foram feitas, exclusivamente, através dos exames das exsicatas dos espécimes obtidos durante este estudo e nos trabalhos desenvolvidos na APA (Lima \& Melo 2015, Machado-Filho 2011). Em níveis de gênero e espécie, as identificações foram fundamentadas na literatura especializada, principalmente através dos estudos de Barbosa-Fevereiro (1977), Irwin \& Barneby (1982), Barneby (1991), Córdula et al. (2009), Fortuna-Perez (2009) e Queiroz (2006, 2009), além de outros de cunho taxonômico sobre Leguminosae.

Para a designação das estruturas morfológicas adotaram-se os termos designados em Radford et al. (1974). Chaves de identificação foram produzidas para subfamílias, gêneros e espécies, e estampas destacando caracteres diagnósticos de gêneros e espécies. Também são apresentados comentários sobre 


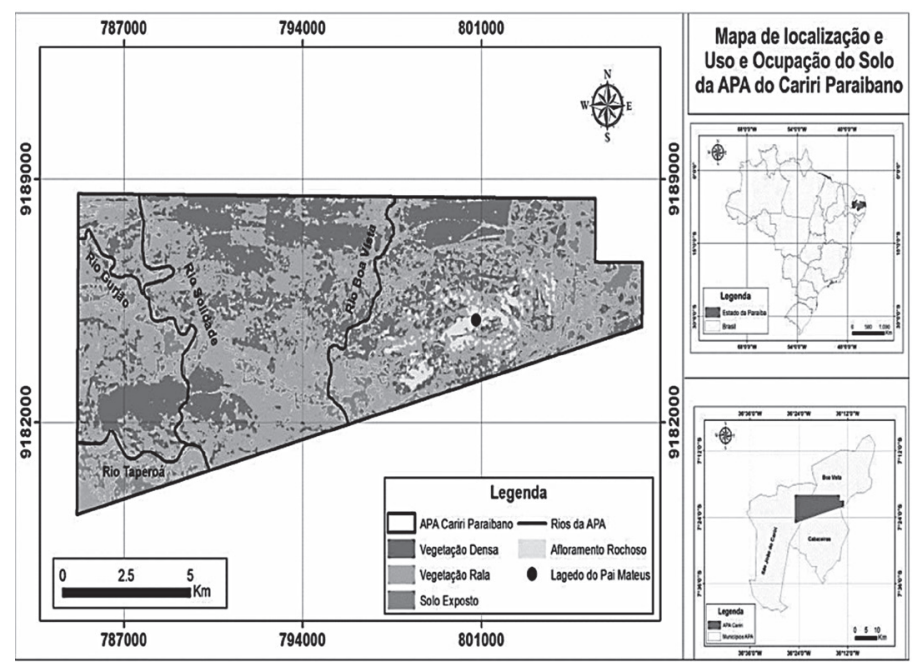

Figura 1. Localização da área estudada, situando a APA do Cariri nos municípios paraibanos abrangidos pela mesma e suas características fisionômicas.

Figure 1. Location of the study area, placing the APA do Cariri in the Paraíba municipalities covered by it and their physiognomic characteristics.

distribuição geográfica e habitats, para as espécies registradas na área de estudo.

\section{Resultados e Discussão}

Foram registradas 31 espécies distribuídas em 18 gêneros dos quais nove pertencem à subfamília Papilionoideae, seguida de Caesalpinioideae, representada por seis gêneros, e por três gêneros pertencentes à Mimosoideae (tabela 1).

Chave para as subfamílias de Leguminosae

1. Flores papilionadas, com as pétalas diferenciadas em estandarte, alas e carena; estandarte mais externo no botão; sementes geralmente reniformes com hilo alongado, localizado na porção mediana da semente Papilionoideae

1. Flores não papilionadas, actinomorfas ou zigomorfas, quando zigomorfas apresentando um estandarte diferenciado tendo disposição mais internanobotão; sementesnãoreniformes com hilo diminuto, localizado na extremidade da semente

2. Inflorescências em espigas ou glomérulos; flores actinomorfas diminutas, com os estames representando a parte atrativa da flor .... Mimosoideae

2. Inflorescências em racemos ou panículas; flores relativamente grandes, com a corola constituindo a parte atrativa da flor . Caesalpinioideae

\section{Caesalpinioideae}

Chave para as espécies da subfamília Caesalpinioideae

1. Folhas simples, divididas no ápice, ou bifolioladas 2. Plantas arbustivas; lâmina foliar de ápice bilobado

3. Botões florais clavados, não estriados; pétalas brancas, obovais; estípite menor que $2 \mathrm{~cm}$ compr. Bauhinia cheilantha

3. Botões florais cilíndricos, estriados; pétalas brancas, lineares; estípite maior que $2 \mathrm{~cm}$ compr. Bauhinia subclavata

2. Plantas herbáceas ou arbóreas; lâmina foliar bifoliolada

4. Árvore; pecíolo 13-17 mm compr.; flores actinomorfas, com 4 sépalas, pétalas brancas e 10 estames; fruto cilíndrico, 8-15 cm compr..... Hymenaea courbaril

4. Erva; pecíolo 3-6 mm compr.; flores zigomorfas, com 5 sépalas, pétalas amarelas e 5 estames; fruto linear, 3,5-4 cm compr. .... Chamaecrista rotundifolia

1. Folhas pinadas ou bipinadas

5. Folhas pinadas; sem pétala vexilar diferenciada por mácula vermelha ou alaranjada

6. Folhas com 2 ou 3 pares de folíolos

7. Folhas com 3 pares de folíolos; fruto ligeiramente compresso ... Senna obtusifolia

7. Folhas com 2 pares de folíolos; fruto cilíndrico ou compresso 
8. Flores menores que $3 \mathrm{~cm}$ diâm., com uma das pétalas diferenciada em cuculo e 10 estames; fruto compresso, menor que $5 \mathrm{~cm}$ compr. . Chamaecrista belemii var. belemii

8. Flores maiores que $3 \mathrm{~cm}$ diâm., sem pétala diferenciada em cuculo e 7 estames; fruto cilíndrico, maior que $5 \mathrm{~cm}$ compr.

9. Folíolos papiráceos de base simétrica; pétalas amarelas; estames homomórficos Senna splendida

9. Folíolos cartáceos a coriáceos de base assimétrica; pétalas amarelas-alaranjadas; estames dimórficos Senna macranthera

6. Folhas com 9-22 pares de folíolos

10. Estípulas lanceoladas, $12-13 \mathrm{~mm}$ compr., base secretora alaranjada . Senna martiana

10. Estípulas subuladas, $6,5-8 \mathrm{~mm}$ compr., base não secretora, de cor não diferenciada Senna spectabilis var. excelsa

5. Folhas bipinadas; pétala vexilar diferenciada por máculas vermelhas ou alaranjadas

11. Árvore; tronco com casca descamante; folíolos de base simétrica; fruto legume indeiscente Libidibia ferrea

11.Arbusto; tronco não descamante; folíolos de base assimétrica; fruto legume com deiscência elástica

12. Folha com 1-2 pares de pinas + pina terminal, 4-10 folíolos por pina; inflorescência em panícula Poincianella gardneriana

12. Folha com 3-10 pares de pinas + pina terminal, 11-21 folíolos por pina; inflorescência em racemo ...... Poincianella microphylla

1. Bauhinia cheilantha (Bong.) Steud., Nom. Bot. ed. 2, 1: 191. 1840.

Material examinado: BRASIL. PARAíba: APA do Cariri, Boa Vista, Fazenda Salambaia, 0 $7^{\circ} 18^{\prime} 44,9^{\prime \prime}$, 36 $14 ' 40 " \mathrm{~W}, 400-600$ m, 11-XI-2011, fr., E.A. Lima 225 (ACAM).

Bauhinia cheilantha tem uma distribuição disjunta, ocorrendo em vários Estados das regiões Nordeste, Centro-Oeste e Sudeste do Brasil, em florestas estacionais (Queiroz 2009, Vaz 2014). Na Caatinga, $B$. cheilantha ocorre em áreas de vegetação rala, em solos pobres, em elevações menores de $600 \mathrm{~m}$ (Queiroz 2009).

Esta espécie diferencia-se de B. subclavata principalmente pelos botões sem estrias e pétalas mais largas $(\geq 20 \mathrm{~mm})$.

2. Bauhinia subclavata Benth. in Mart., Fl. Brasil. 15(2): 188. 1870.

Material examinado: BRASIL. PARAíba: APA do Cariri, Boa Vista, Fazenda Salambaia, 07018'44,9"S, 36²14'40"W, 400-600 m, 10-VI-2011, fl., fr., E.A. Lima 175 (ACAM).

Bauhinia subclavata ocorre principalmente na Caatinga situada ao norte da região Nordeste (Queiroz 2009), no corredor seco entre o Cerrado e a Caatinga (Vaz \& Tozzi 2003). De acordo com Cardoso \& Queiroz (2007), é comum às áreas de solo arenoso e embasamento cristalino.

Diferencia-se de $B$. cheilantha, da qual é morfologicamente assemelhada, por apresentar botões estriados no ápice e por suas pétalas lineares (largura $\leq 2 \mathrm{~mm}$ ).

3. Chamaecrista belemii (H.S. Irwin \& Barneby) H.S. Irwin \& Barneby var. belemii, Mem. New York Bot. Gard. 35: 660. 1982.

Material examinado: BRASIL. Paraíba: APA do Cariri, Boa Vista, Fazenda Salambaia, 07¹8'44,9"S, $36^{\circ} 14^{\prime} 40 " \mathrm{~W}, 400-600$ m, 11-II-2011, fl., fr., E.A. Lima 59 (ACAM).

Aparentemente endêmica da Caatinga (Queiroz 2009), sendo anteriormente referida apenas para os Estados de Pernambuco, Bahia e Sergipe (Souza \& Bortoluzzi 2014), ocorre principalmente em solos arenosos (Queiroz 2009). Nesse trabalho constitui novo registro para o Estado da Paraíba.

Chamaecrista belemii var. belemii é de difícil reconhecimento, especialmente por apresentar características intermediárias de outras espécies e até de outros gêneros, sendo de fundamental importância para sua elucidação as observações em campo, de sua arquitetura bastante ramificada (Queiroz 2009), e em laboratório, de seu aspecto glabro.

4. Chamaecrista rotundifolia (Pers.) Greene, Pittonia 4: 31. 1899.

Material examinado: BRASIL. Paraíba: APA do Cariri, Boa Vista, Fazenda Salambaia, 07²18'44,9"S, 
Tabela 1. Lista de espécies de Leguminosae Juss. com respectivo hábito de crescimento e subfamília coletadas na Área de Proteção Ambiental (APA) do Cariri, Paraíba, Brasil. * Endêmicas. Erv: Erva. Arb: Arbusto. Trep: Trepadeira. Liana: Liana. Arv: Árvore.

Table 1. Checklist of Leguminosae Juss. with respective growth habit and subfamily collected at the APA do Cariri, Paraíba State, Brazil. * Endemics. Erv: Herb. Arb: Shrub. Trep: Climber. Liana: Liana. Arv: Tree.

\begin{tabular}{|c|c|c|}
\hline Espécie & Hábito & Subfamília \\
\hline Bauhinia cheilantha (Bong.) Steud. & Arb & Caesalpinioideae \\
\hline Bauhinia subclavata Benth. & Arb & Caesalpinioideae \\
\hline $\begin{array}{l}\text { Chamaecrista belemii (H.S. Irwin \& Barneby) H.S. Irwin \& } \\
\text { Barneby var. belemii* }\end{array}$ & Arb & Caesalpinioideae \\
\hline Chamaecrista rotundifolia (Pers.) Greene & Erv & Caesalpinioideae \\
\hline Hymenaea courbaril L. & Árv & Caesalpinioideae \\
\hline Libidibia ferrea (Mart. ex Tul.) L.P. Queiroz var. ferrea & Árv & Caesalpinioideae \\
\hline Poincianella gardneriana (Benth.) L.P. Queiroz* & Arb & Caesalpinioideae \\
\hline Poincianella microphylla (Mart. ex G. Don) L.P. Queiroz* & Arb & Caesalpinioideae \\
\hline Senna macranthera (DC. ex Collad.) Irwin \& Barneby & Arb & Caesalpinioideae \\
\hline Senna martiana (Benth.) Irwin \& Barneby* & Arb & Caesalpinioideae \\
\hline Senna obtusifolia (L.) Irwin \& Barneby & Erv & Caesalpinioideae \\
\hline Senna spectabilis var. excelsa (Schrad.) H.S. Irwin \& Barneby & Árv & Caesalpinioideae \\
\hline Senna splendida (Vogel) Irwin \& Barneby & Arb & Caesalpinioideae \\
\hline Anadenanthera colubrina var. cebil (Griseb.) Altschul. & Árv & Mimosoideae \\
\hline Mimosa ophthalmocentra Mart. ex Benth. & Arb & Mimosoideae \\
\hline Mimosa tenuiflora (Wiild.) Poir. & Arb & Mimosoideae \\
\hline Piptadenia stipulacea (Benth.) Ducke* & Arb & Mimosoideae \\
\hline Canavalia brasiliensis Mart. ex Benth. & Trep & Papilionoideae \\
\hline Centrosema virginianum (L.) Benth. & Trep & Papilionoideae \\
\hline Desmodium glabrum (Mill.) DC. & Erv & Papilionoideae \\
\hline Dioclea grandiflora Mart. ex Benth.* & Liana & Papilionoideae \\
\hline Dioclea violacea Mart. ex Benth. & Liana & Papilionoideae \\
\hline Erythrina velutina Willd. & Árv & Papilionoideae \\
\hline Indigofera blanchetiana Benth.* & Arb & Papilionoideae \\
\hline Indigofera suffruticosa Mill. & Arb & Papilionoideae \\
\hline Stylosanthes viscosa (L.) Sw. & Erva & Papilionoideae \\
\hline Vigna halophila (Piper) Maréchal, Mascherpa \& Stainier & Trep & Papilionoideae \\
\hline Zornia echinocarpa (Moric.) Benth. & Arb & Papilionoideae \\
\hline Zornia latifolia $\mathrm{Sm}$. & Erv & Papilionoideae \\
\hline Zornia leptophylla (Benth.) Pittier & Erv & Papilionoideae \\
\hline Zornia myriadena Benth. & Erv & Papilionoideae \\
\hline
\end{tabular}


36 $144^{\prime} 40^{\prime \prime} \mathrm{W}, 400-600$ m, 3-VIII-2010, fl., fr., E.A. Lima 189 (ACAM).

Chamaecrista rotundifolia é uma espécie encontrada do sudeste dos Estados Unidos até o extremo sul da América do Sul (Queiroz 2009). Habita ambientes ruderais, em solos arenosos ou pedregosos (Camargo \& Miotto 2004).

Esta espécie é facilmente distinguível de Chamaecrista belemii var. belemii devido ao seu hábito herbáceo, com ramos prostrados, e folhas bifolioladas.

\section{Hymenaea courbaril L., Sp. P1.: 1192. 1753.}

Material examinado: BRASIL. Paraíba: APA do Cariri, Boa Vista, Fazenda Salambaia, 07²12'10,3"S, $36^{\circ} 10^{\prime} 02,2^{\prime \prime} \mathrm{W}, 400-600 \mathrm{~m}, 3-\mathrm{V}-2011$, fl., fr., H.O. Machado-Filho 146 (ACAM).

Hymenaea courbaril apresenta uma ampla distribuição, ocorrendo do Sul do México e Antilhas até o Sudeste do Brasil (Lee \& Langenheim 1975).

Dentre as espécies de Caesalpinioideae encontradas na APA do Cariri, $H$. courbaril é de fácil reconhecimento por apresentar porte arbóreo, podendo alcançar $9 \mathrm{~m}$ de altura, bem como pelas folhas dísticas e pelo legume bacóide.

6. Libidibia ferrea (Mart. ex Tul.) L.P. Queiroz var. ferrea, Arch. Mus. Hist., Nat. Paris. 4: 138. 1844. Figuras 2 b, 4 b-c

Material examinado: BRASIL. PARAíbA: APA do Cariri, Boa Vista, Lajedo do Bravo, $469 \mathrm{~m}$, 07²1'56,72"S, 36² 14'34,3"W, 15-X-2011, fr., P.S. M. Ferreira 1 (ACAM). BRASIL. PARAíBA: APA do Cariri, Boa Vista, Fazenda Salambaia, 0 $7^{\circ} 12^{\prime} 10,3^{\prime \prime}$, $36^{\circ} 10^{\prime} 02,2^{\prime \prime} \mathrm{W}, 400-600 \mathrm{~m}, 11-\mathrm{II}-2011$, fr., H.O. Machado-Filho 92 (ACAM).

Libidibia ferrea var. ferrea é uma espécie típica de Caatinga, sendo normalmente observada em margens de curso de rios temporários, sendo menos comum na Caatinga arbórea, ocorrendo em elevações entre 300 e 750 m (Córdula et al. 2009).

$\mathrm{O}$ tronco variegado devido à descamação, e as pétalas amarelo-ouro de Libidibia ferrea var. ferro, constituem importantes características para a sua identificação em campo. Esta espécie apresentou nos exemplares da APA do Cariri o número fixo de 3 pares de pinas.

7. Poincianella gardneriana (Benth.) L.P. Queiroz, Leguminosas da Caatinga: 123. 2009.

Material examinado: BRASIL. Paraíba: APA do Cariri, Boa Vista, Fazenda Salambaia, 07²12'10,3"S,
360'02,2"W, 400-600 m, 11-II-2011, fl., fr., H.O. Machado-Filho 119 (ACAM).

Poincianella gardneriana é considerada uma espécie endêmica da Caatinga, e ocorre dos Estados do Piauí, Ceará, Rio Grande do Norte, Paraíba, Pernambuco e Bahia (Queiroz 2009, Lewis 2014). Habita principalmente a Caatinga aberta, sobre solos arenosos ou latossolos, em elevações inferiores a $600 \mathrm{~m}$ (Queiroz 2009).

Apresenta características intermediárias de $P$. pyramidalis var. pyramidalis, tendo como características distintivas a articulação do pedicelo, logo abaixo do hipanto em P. gardneriana e de 10-12 mm abaixo do hipanto em $P$. pyramidalis var. pyramidalis.

8. Poincianella microphylla (Mart. ex G. Don) L.P. Queiroz, Leguminosas da Caatinga: 274. 2009.

Material examinado: BRASIL. PARAíba: APA do Cariri, Boa Vista, Fazenda Salambaia, 07²12'10,3"S, $36^{\circ} 10^{\prime} 02,2^{\prime \prime} \mathrm{W}, 400-600 \mathrm{~m}, 11-\mathrm{II}-2011$, fl., fr., H.O. Machado-Filho 118 (ACAM).

Poincianella microphylla até o momento havia sido registrada apenas para os Estados do Piauí, Pernambuco e Bahia, sendo acreditada como endêmica da Caatinga (Queiroz 2009, Lewis 2014). Esta espécie típica de solos arenosos ocorre em altitudes inferiores a 600 m (Queiroz 2009). Nesse trabalho está sendo referida pela primeira vez para o Estado da Paraíba.

Poincianella microphylla diferencia-se de P. gardneriana, com a qual é morfologicamente assemelhada, por apresentar porte e estruturas vegetativas menores, além de sua inflorescência característica, do tipo racemo, em detrimento à panícula de $P$. gardneriana.

9. Senna macranthera (DC. ex Collad.) Irwin \& Bernaby, Mem. New York Bot. Gard. 35: 181. 1982.

Material examinado: BRASIL. PARAíBA: APA do Cariri, Boa Vista, Fazenda Salambaia, 07²12'10,3"S, $36^{\circ} 10^{\prime} 02,2^{\prime \prime} \mathrm{W}, 400-600 \mathrm{~m}, 11-\mathrm{II}-2011$, fl., fr., H.O. Machado-Filho 07 (ACAM).

Senna macranthera é uma espécie polimórfica distribuída na América do Sul, desde a Venezuela até o Sul do Brasil, ocorre principalmente no Nordeste e Sudeste do país (Queiroz 2009, Souza \& Bortoluzzi 2014), nos mais variados tipos de habitats abertos (Queiroz 2009). 
Senna macranthera compartilha com $S$. splendida os dois pares de folíolos e as flores grandes $(>4 \mathrm{~cm}$ diâm.), podendo ser diferenciada desta última por apresentar folíolos maiores $(>4 \mathrm{~cm})$, pubescentes e com a nervura principal deslocada da base, flores menores $(\leq 6 \mathrm{~cm}$ diâm.) com pétalas amarelasalaranjadas.

10. Senna martiana (Benth.) Irwin \& Barneby, Mem. New York Bot. Gard. 35: 465. 1982.

Figuras 2 c, 4 a

Material examinado: BRASIL. Paraíba: APA do Cariri, Boa Vista, Lajedo do Bravo, $473 \mathrm{~m}$, $07^{\circ} 21^{\prime} 58,89^{\prime \prime} \mathrm{S}, 36^{\circ} 14^{\prime} 40,47^{\prime \prime} \mathrm{W}, 15-\mathrm{X}-2011$, fl., fr., P.S.M. Ferreira 3 (ACAM).

Senna martiana é uma espécie endêmica da Caatinga, ocorre no Rio Grande do Norte, e do sudeste do Piauí até o norte da Bahia (Irwin \& Barneby 1982), sendo comum em solo arenoso, em elevações inferiores a $500 \mathrm{~m}$, podendo ser uma colonizadora de áreas degradadas (Queiroz 2009).

Senna martiana pode ser reconhecida facilmente por apresentar estípulas alaranjadas, transformadas em nectários extraflorais, além de seus ramos com entrenós muito curtos.

11. Senna obtusifolia (L.) Irwin \& Barneby, Mem. New York Bot. Gard. 35: 252. 1982.

Material examinado: BRASIL. PARAíba: APA do Cariri, Boa Vista, Fazenda Salambaia, 0 $7^{\circ} 18^{\prime} 44,9^{\prime \prime}$, 36²14'40"W, 400-600 m, 11-IX-2010, fl., E.A. Lima 103 (ACAM).

Senna obtusifolia distribui-se do México até a Argentina, mas também ocorre espontaneamente nos trópicos da África e Ásia (Irwin \& Barneby 1982, Córdula et al. 2009). Na Caatinga é comumente encontrada em ambientes degradados em margens de rios e lagos, em elevações de até $1000 \mathrm{~m}$ (Queiroz 2009). Esta espécie é considerada uma invasora infestante, especialmente em campos de cultivo (Simoni et al. 2006).

Dentre as espécies congêneres registradas na APA do Cariri é a única que apresenta hábito herbáceo e folíolos dispostos em exatamente 3 pares.

12. Senna spectabilis (D.C.) H.S. Irwin \& Barneby var. excelsa (Schrad.) H.S. Irwin \& Barneby, Mem. New York Bot. Gard. 35: 604. 1982.

Material examinado: BRASIL. Paraíba: APA do Cariri, Boa Vista, Fazenda Salambaia, 07²12'10,3"S, $36^{\circ} 10^{\prime} 02,2 " \mathrm{~W}, 400-600 \mathrm{~m}, 11-\mathrm{II}-2011$, fl., fr., H.O. Machado-Filho 113 (ACAM).

Senna spectabilis var. excelsa distribui-se principalmente na área de domínio da Caatinga, ocorrendo nas regiões Norte, Nordeste, Centro-Oeste e Sudeste do Brasil (Queiroz 2009, Souza \& Bortoluzzi 2014). Ocorre sobre diferentes tipos de solos, em elevações que chegam a 1000 m (Queiroz 2009).

A espécie pode ser distinguida de $S$. martiana por suas estípulas não serem diferenciadas em nectários, além de possuir entrenós mais longos, racemos menores, frutos cilíndricos e mais longos $(>8 \mathrm{~cm})$.

13. Senna splendida (Vogel) Irwin \& Barneby, Mem. New York Bot. Gard. 35: 190. 1982.

Material examinado: BRASIL. PARAíba: APA do Cariri, Boa Vista, Fazenda Salambaia, 07²18 $449^{\prime \prime}$, 36 14 '40"W, 400-600 m, 9-X-2010, fl., E.A. Lima 226 (ACAM).

Senna splendida ocorre nas regiões Nordeste, Centro-Oeste, Sudeste e Sul do Brasil (Souza \& Bortoluzzi 2014). Habita geralmente florestas mais úmidas, geralmente em áreas de transição entre remanescentes de Mata Atlântica e Caatinga (Queiroz 2009).

Pode ser diferenciada em campo de $S$. macranthera por apresentar folíolos menores $(<4 \mathrm{~cm})$ e pelas flores amarelas.

\section{Mimosoideae}

Chave para as espécies da subfamília Mimosoideae

1. Árvore, ramos inermes; inflorescência glomérulo; fruto folículo ... Anadenanthera colubrina

1. Arbusto, ramos armados por acúleos; inflorescência racemo; fruto legume ou craspédio

2. Fruto legume; flores pentâmeras; ovário exserto da flor Piptadenia stipulacea

2. Fruto craspédio; flores tetrâmeras; ovário não exserto da flor

3. Folíolos com pontuações glandulares; corola cilíndrica em secção transversal; fruto estipitado Mimosa tenuiflora

3. Folíolos não pontuado-glandulares; corola quadrangular em secção transversal; fruto séssil Mimosa ophthalmocentra 

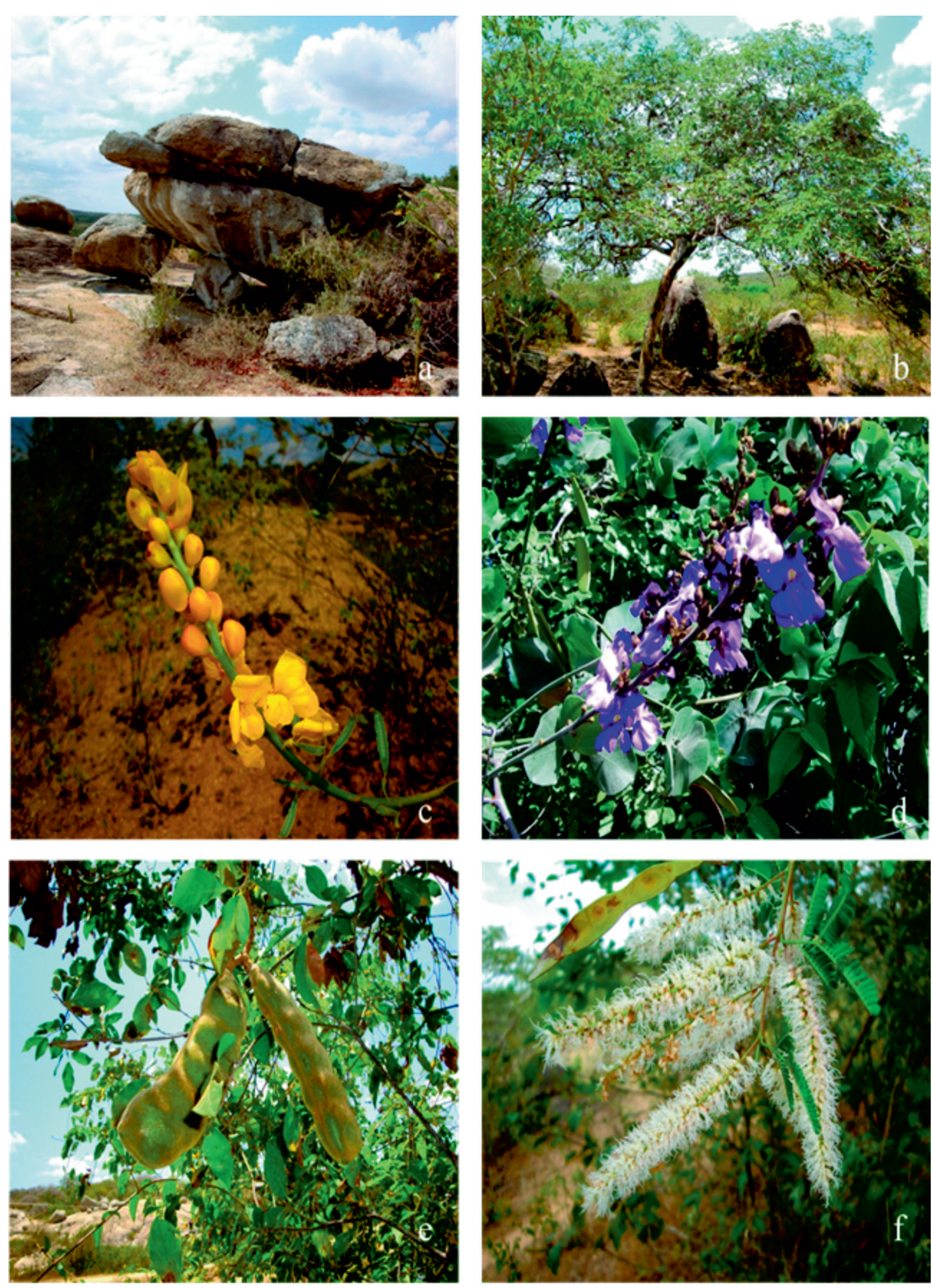

Figura 2. Aspecto da área de estudo e imagens de espécies de leguminosas coletadas, APA do Cariri, Paraíba, Brasil. a. Área de estudo com afloramento rochoso em caatinga arbustivo-aberta. b. Libidibia ferrea var. ferrea. Hábito. c. Senna martiana. Inflorescência. d, e. Dioclea grandiflora. d. Flores. e. Frutos. f. Mimosa ophthalmocentra. Inflorescência. (Fotos: P.S.M. Ferreira).

Figure 2. Aspect of the studied area and images of species of Leguminosae collected, APA do Cariri, Paraíba State, Brazil. a. Study area with rocky outcrop in caatinga shrubby opened. b. Libidibia ferrea var. ferrea. Habit. c. Senna martiana. Inflorescence. d, e. Dioclea grandiflora. d. Flowers. e. Fruits. f. Mimosa ophthalmocentra. Inflorescence. (Photos: P.S.M. Ferreira). 
14. Anadenanthera colubrina var. cebil (Griseb.) Altschul., Contr. Gray Herb. 193: 53. 1964.

Figura $4 \mathrm{f}$

Material examinado: BRASIL. Paraíba: APA do Cariri, Boa Vista, Lajedo do Bravo, $480 \mathrm{~m}$, $07^{\circ} 21^{\prime} 54,69^{\prime \prime} \mathrm{S}, 36^{\circ} 14^{\prime} 39,40^{\prime \prime} \mathrm{W}, 15-\mathrm{X}-2011$, fr., P.S.M. Ferreira 2 (ACAM). BRASIL. PARAíBA: APA do Cariri, Boa Vista, Fazenda Salambaia, $07^{\circ} 12^{\prime} 10,3^{\prime \prime}$, $36^{\circ} 10^{\prime} 02,2^{\prime \prime} \mathrm{W}, 400-600 \mathrm{~m}, 11-\mathrm{X}-2011$, fr., H.O. Machado-Filho 141 (ACAM).

Esta variedade comumente encontrada na Caatinga arbórea, em elevações que variam de 300 a $800 \mathrm{~m}$, pode apresentar uma copa de até $10 \mathrm{~m}$ de altura (Queiroz 2009). É uma planta decídua, heliófita, e característica de mata secundária (Ortolani et al. 2010), comum de solos com embasamento cristalino (Cardoso \& Queiroz 2007).

Caracteriza-se morfologicamente por apresentar grande número de pinas (15 a 22 pares), com folíolos oblongo-lineares com nervação saliente em ambas as faces, possuindo o fruto típico folículo com margens irregulares, além das inflorescências em glomérulos homomórficos.

15. Mimosa ophthalmocentra Mart. ex Benth., Trans. Linn. Soc. London 30: 415. 1875.

Figuras 2 f, 3 a, 4 a

Material examinado: BRASIL. Paraíba: APA do Cariri, Boa Vista, Lajedo do Bravo, $465 \mathrm{~m}$, 07²1'58,26"S, 36²14'30,11"W, 15-X-2011, fl., fr., P.S.M. Ferreira 5 (ACAM).

Mimosa ophthalmocentra ocorre tanto em Caatinga arenosa quanto na depressão sertaneja em bancos arenosos de rios sujeitos a inundações periódicas (Córdula et al. 2009, Lacerda et al. 2007, Queiroz 2009).

A espécie Mimosa ophthalmocentra tem como características marcantes, em contraste com
M. tenuiflora, a corola quadrangular em secção transversal, folíolos sem pontuações glandulares e frutos sésseis.

16. Mimosa tenuiflora (Willd.) Poir., Encycl. (Lamarck), Suppl. 1: 82. 1811.

Material examinado: BRASIL. PARAíba: APA do Cariri, Boa Vista, Fazenda Salambaia, 07 $12^{\prime} 10,3^{\prime \prime S}$, $36^{\circ} 10^{\prime} 02,2^{\prime \prime} \mathrm{W}, 400-600 \mathrm{~m}, 11-\mathrm{II}-2011$, fl., fr., H.O. Machado-Filho s.n. (ACAM).

Mimosa tenuiflora é uma espécie de distribuição em vários Estados do Nordeste do Brasil, no Norte da Venezuela, Colômbia, Sul do México, Honduras e El Salvador, habitando principalmente lugares sujeitos à seca periódica (Barneby 1991). Na APA do Cariri foi observada formando grandes e densos agrupamentos de indivíduos.

Distingue-se de sua congênere na área de estudo principalmente por apresentar folíolos com pontuações glandulares.

17. Piptadenia stipulacea (Benth.) Ducke, Arq. Jard. Bot. Rio de Janeiro 5: 126. 1930.

Material examinado: BRASIL. Paraíba: APA do Cariri, Boa Vista, Fazenda Salambaia, 07¹8'44,9"S, 36 14 '40"W, 400-600 m, 14-X-2010, fl., E.A. Lima s.n. (ACAM 1837).

Piptadenia stipulacea é uma espécie endêmica da Caatinga, ocorre em todos os Estados do Nordeste brasileiro excetuando-se o Maranhão (Morim 2014), em diferentes tipos de solo, em elevações inferiores a $700 \mathrm{~m}$ (Queiroz 2009). Morfologicamente assemelha-se aos representantes do gênero Mimosa, podendo ser facilmente reconhecível por apresentar fruto em legume e folhas com mais de sete pares de pinas.

\section{Papilionoideae}

Chave para as espécies da subfamília Papilionoideae

1. Árvore; tronco revestido por acúleos lenhosos; flores maiores que $50 \mathrm{~mm}$ compr., vermelhasalaranjadas, estames excertos à corola; sementes vermelhas ... Erythrina velutina

1. Ervas, arbustos, trepadeiras, lianas; tronco (ramos) sem acúleos lenhosos; flores menores que $50 \mathrm{~mm}$ compr., roxas, lilases, róseas, amarelas ou vermelhas, estames não excertos à corola; sementes não vermelhas

2. Folhas com exatamente 3 folíolos

3. Flores amarelas, sésseis, menores que $6 \mathrm{~mm}$ compr., corola com pétalas amarelas, hipanto tubuloso; ramos viscosos Stylosanthes viscosa

3. Flores liláses, pediceladas, maiores que $6 \mathrm{~mm}$ compr., colora com pétalas não amarelas, hipanto não tubuloso ou ausente; ramos não viscosos 
4. Inflorescências 40-100 mm compr.

5. Pecíolo $48 \mathrm{~mm}$ compr.; pseudo-racemo terminal; legume $18,5 \mathrm{~cm}$ compr.

Dioclea grandiflora

5. Pecíolo 60-75 mm compr.; pseudo-racemo axilar; legume 13-15 cm compr. Dioclea violacea

4. Inflorescências menores que $27 \mathrm{~mm}$ compr.

6. Estandarte em posição superior às demais pétalas

7. Trepadeira; pétalas roxas, com alas e carena não unidas; folíolo terminal $78 \mathrm{~mm}$ compr.; fruto legume Vigna halophila

7. Arbusto; pétalas vermelhas, com alas e carena unidas; folíolo terminal 19-35 mm compr.; fruto lomento Desmodium glabrum

6. Estandarte em posição inferior às demais pétalas

8. Cálice bilabiado; corola com estandarte não calcarado; pseudo-racemo $6,5-17 \mathrm{~cm}$ compr., com mais de 2 flores Canavalia brasiliensis

8. Cálice campanulado; corola com estandarte calcarado; racemo 1,8 cm compr., 1-2 flores Centrosema virginianum

2. Folhas com 2,4 ou mais folíolos $(\neq 3)$

9. Folhas com exatamente 2 ou 4 folíolos; inflorescência em espiga ou flores solitárias, sésseis, amarelas; fruto lomento

10. Folíolos 4, com disposição palmada; flores solitárias axilares

11. Arbusto; folíolos distais ca. $17 \mathrm{~mm}$ compr.; artículos equinados Zornia echinocarpa

11. Erva; folíolos distais 8-22 mm compr.; artículos não equinados Zornia myriadena 10. Folíolos 2; inflorescências em espigas axilares

12. Estípulas caducas; espigas $4,8 \mathrm{~cm}$ compr.; folíolos das folhas distais pontuados .... Zornia leptophylla

12. Estípulas persistentes; espigas 7-13,5 cm compr.; folíolos não pontuados Zornia latifolia

9. Folhas com mais de 2 folíolos; inflorescência em racemo e flores pediceladas, avermelhadas ou róseas; fruto legume 13. Pecíolo 7-9 mm compr.; racemos 8-25 cm compr.; flores róseas Indigofera blanchetiana 13. Pecíolo 15 mm compr.; racemos 1,3-3,5 cm compr.; flores vermelho-salmão ........ Indigofera suffruticosa

18. Canavalia brasiliensis Mart. ex Benth., Comm. Leg. Gen.: 71. 1837.

Material examinado: BRASIL. Paraíba: APA do Cariri, Boa Vista, Fazenda Salambaia, 07 $18^{\prime} 449^{\prime \prime}$, 36 $14 ' 40 " \mathrm{~W}, 400-600$ m, 14-VIII-2010, fl., fr., E.A. Lima 231 (ACAM).

Canavalia brasiliensis ocorre nas regiões Norte, Nordeste, Centro-Oeste e Sudeste do Brasil, no entano, é essencialmente uma espécie de Caatinga, que ocorre em áreas antropizadas, sobre solos argilosos ou arenoargilosos, em elevações inferiores a $600 \mathrm{~m}$ (Queiroz 2009, 2014).

No que concerne ao hábito, Canavalia brasiliensis assemelha-se morfologicamente à Centrosema virginianum, podendo ser diferenciada desta por apresentar inflorescência marcadamente mais longa, com 6,5 a $17 \mathrm{~cm}$ compr., portando maior número de flores, geralmente acima de 2 .

19. Centrosema virginianum (L.) Benth., Comm. Leg. Gen.: 56. 1837.

Material examinado: BRASIL. Paraíba: APA do Cariri, Boa Vista, Fazenda Salambaia, 07²18'44,9"S,
36²14'400"W, 400-600 m, 14-VIII-2010, fl., fr., E.A. Lima 178 (ACAM).

Centrosema virginianum ocorre do Leste dos Estados Unidos até a Argentina, tornando-se naturalizada na África ocidental. Espécie comum de áreas antropizadas, habita sobre diversos tipos de solos, em elevações inferiores a $500 \mathrm{~m}$ (Córdula et al. 2009, Queiroz 2009).

Esta espécie pode ser reconhecida principalmente por suas flores lilases vistosas, com estandarte ressupinado.

20. Desmodium glabrum (Mill.) DC., Prodr. 2: 338. 1825.

Material examinado: BRASIL. PARAíba: APA do Cariri, Boa Vista, Fazenda Salambaia, 07018'44,9"S, 36² 14 '40"W, 400-600 m, 5-VIII-2011, fr., E.A. Lima 201 (ACAM).

Desmodium glabrum é uma espécie ruderal, ocorre do México ao Norte da Argentina (Queiroz 2009). Na Caatinga, comporta-se como planta invasora de áreas antropizadas, em elevações de até 1.000 m (Córdula et al. 2009, Queiroz 2009). 

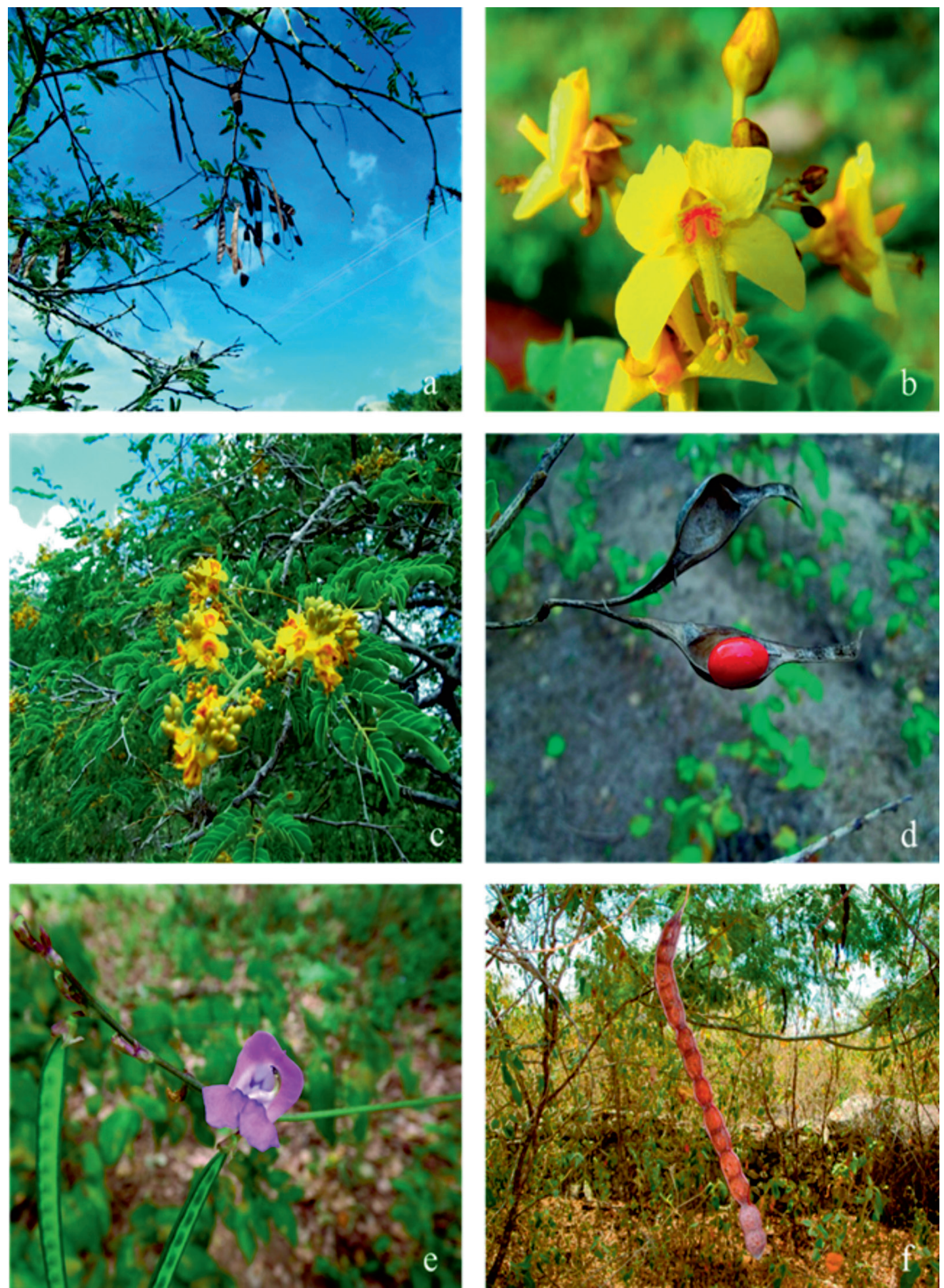

Figura 3. Imagens de representantes de Leguminosae coletadas na APA do Cariri, Paraíba, Brasil. a. Mimosa ophthalmocentra (P.S.M. Ferreira 5 (ACAM)). Fruto. b, c. Libidibia ferrea var. ferrea (H.O. Machado-Filho 92 (ACAM), P.S.M. Ferreira 1 (ACAM)). Ramo reprodutivo. d. Erythrina velutina (P.S.M. Ferreira 6 (ACAM)). Fruto e semente. e. Vigna halophila (E.A. Lima 230 (ACAM)). Ramo reprodutivo. f. Anadenanthera colubrina var. cebil (H.O. Machado-Filho 141 (ACAM), P.S.M. Ferreira 2 (ACAM)). Fruto.

Figure 3. Images of representatives of Leguminosae collected at the APA do Cariri, Paraíba State, Brazil. a. Mimosa ophthalmocentra (P.S.M. Ferreira 5 (ACAM)). Fruit. b, c. Libidibia ferrea var. ferrea (H.O. Machado-Filho 92 (ACAM), P.S.M. Ferreira 1 (ACAM)). reproductive branch. d. Erythrina velutina (P.S.M. Ferreira 6 (ACAM)). Fruit and seed. e. Vigna halophila (E.A. Lima 230 (ACAM)). Reproductive branch. f. Anadenanthera colubrina var. cebil (H.O. Machado-Filho 141 (ACAM), P.S.M. Ferreira 2 (ACAM)). Fruit. 
O fruto em lomento com o artículo terminal aumentado em comparação com os das demais espécies, além do formato reniforme, são características que permitem o pronto reconhecimento desta espécie.

21. Dioclea grandiflora Mart. ex Benth., Comm. Leg. Gen.: 68. 1837.

Figuras 2 b, 4 b

Material examinado: BRASIL. Paraíba: APA do Cariri, Boa Vista, Lajedo do Bravo, $467 \mathrm{~m}$, $07^{\circ} 21^{\prime} 58,1^{\prime \prime S}, 36^{\circ} 14 ' 34,7^{\prime \prime} \mathrm{W}, 15-\mathrm{X}-2011$, fl., fr., P.S.M. Ferreira 4 (ACAM).

Dioclea grandiflora é endêmica da Caatinga, distribuindo-se em todo o semiárido nordestino excetuando-se o Maranhão (Queiroz 2014).

$\mathrm{Na}$ ausência de suas inflorescências, que se apresentam exuberantes, a espécie pode ser identificada por formar densos aglomerados sobre outras plantas, e pelos grandes legumes vilosos, canescentes (Córdula et al. 2009), de textura aveludada.

22. Dioclea violacea Mart. ex Benth., Comm. Leg. Gen.: 69. 1837.

Material examinado: BRASIL. Paraíba: APA do Cariri, Boa Vista, Fazenda Salambaia, 07²12'10,3"S, $36^{\circ} 10^{\prime} 02,2^{\prime \prime} \mathrm{W}, 400-600 \mathrm{~m}, 11-\mathrm{II}-2011$, fl., fr., H.O. Machado-Filho 116 (ACAM).

Dioclea violacea é uma espécie de Mata Atlântica, ocorrendo no Leste do Brasil, chegando ao Norte da Argentina e Paraguai (Queiroz 2009). Neste trabalho, é registrada pela primeira vez para o Estado da Paraíba.

Pode ser distinguida de D. grandiflora por apresentar inflorescências axilares e frutos menores que $17 \mathrm{~cm}$ de comprimento, enquanto que esta última exibe inflorescências terminais e frutos em média maiores que $17 \mathrm{~cm}$ de comprimento.

23. Erythrina velutina Willd., Ges. Nat. Freunde Berlin Neue Schr. 3: 426. 1801.

Figura $3 \mathrm{~d}$

Material examinado: BRASIL. Paraíba: APA do Cariri, Boa Vista, Lajedo do Bravo, $487 \mathrm{~m}$, $07^{\circ} 21^{\prime} 52,05^{\prime \prime} \mathrm{S}, 36^{\circ} 14^{\prime} 39,27^{\prime \prime} \mathrm{W}, 10-\mathrm{V}-2012$, fr., P.S.M. Ferreira 6 (ACAM).

Erythrina velutina distribui-se na Caatinga e florestas secas no oeste da América do Sul e América Central (Queiroz 2009). Na Caatinga, ocorre frequentemente em áreas de pediplano sobre solos de embasamento cristalino (Cardoso \& Queiroz 2007,
Queiroz 2009). Habita elevações inferiores a $600 \mathrm{~m}$ (Queiroz 2009).

Está espécie é de fácil reconhecimento, mesmo na ausência de material reprodutivo, por possuir um porte avantajado aliado a um tronco espesso com elevações cônicas. Por estas razões, é um elemento florístico que se destaca na paisagem à qual está associado.

24. Indigofera blanchetiana Benth. in Mart., Fl. Bras. 15 (1): 40. 1859.

Material examinado: BRASIL. Paraíba: APA do Cariri, Boa Vista, Fazenda Salambaia, $07^{\circ} 18^{\prime} 44,9^{\prime \prime}$, 36²'4'"W, 400-600 m, 20-VII-2010, fl., E.A. Lima s.n. (ACAM).

Indigofera blanchetiana é provavelmente endêmica de Caatinga (Queiroz 2009), sendo inferida para o Oeste e Sul da região Nordeste e para Minas Gerais, estando associada a solo arenoso, com elevações inferiores a 600 m (Queiroz 2009). Neste trabalho, constitui uma nova ocorrência para a Paraíba.

Esta espécie diferencia-se de I. suffruticosa por apresentar legumes maiores $(\geq 2 \mathrm{~cm})$ e encurvados.

25. Indigofera suffruticosa Mill., Gard. Dict. ed. 8, n. 2. 1768.

Material examinado: BRASIL. Paraíba: APA do Cariri, Boa Vista, Fazenda Salambaia, $07^{\circ} 18^{\prime} 44,9^{\prime \prime}$, 36014'40"W, 400-600 m, 15-IV-2011, fr., E.A. Lima 67 (ACAM).

Indigofera suffruticosa é uma espécie invasora, (Lievens 1992) de áreas antropizadas (Eisinger 1987) sendo comum na Caatinga em áreas alteradas à beira de rios e áreas de cultivo abandonadas (Queiroz 2009).

Distingue-se de Indigofera blanchetiana, principalmente, por apresentar frutos menores $(<2 \mathrm{~cm})$, formando um ângulo de $90^{\circ}$ com o ramo reprodutivo.

26. Stylosanthes viscosa (L.) Sw., Prodr. (Swartz): 108. 1788.

Material examinado: BRASIL. Paraíba: APA do Cariri, Boa Vista, Fazenda Salambaia, $07^{\circ} 18^{\prime} 44,9^{\prime \prime}$ S, $36^{\circ} 14^{\prime} 40^{\prime \prime} \mathrm{W}, 400-600$ m, 15-IV-2011, fr., E.A. Lima 65 (ACAM).

Stylosanthes viscosa ocorre em toda a região entre os Estados Unidos e a Argentina, incluindo as Antilhas, habitando na Caatinga em solos pobres e áreas antropizadas, em elevações de até $850 \mathrm{~m}$ (Queiroz 2009). 


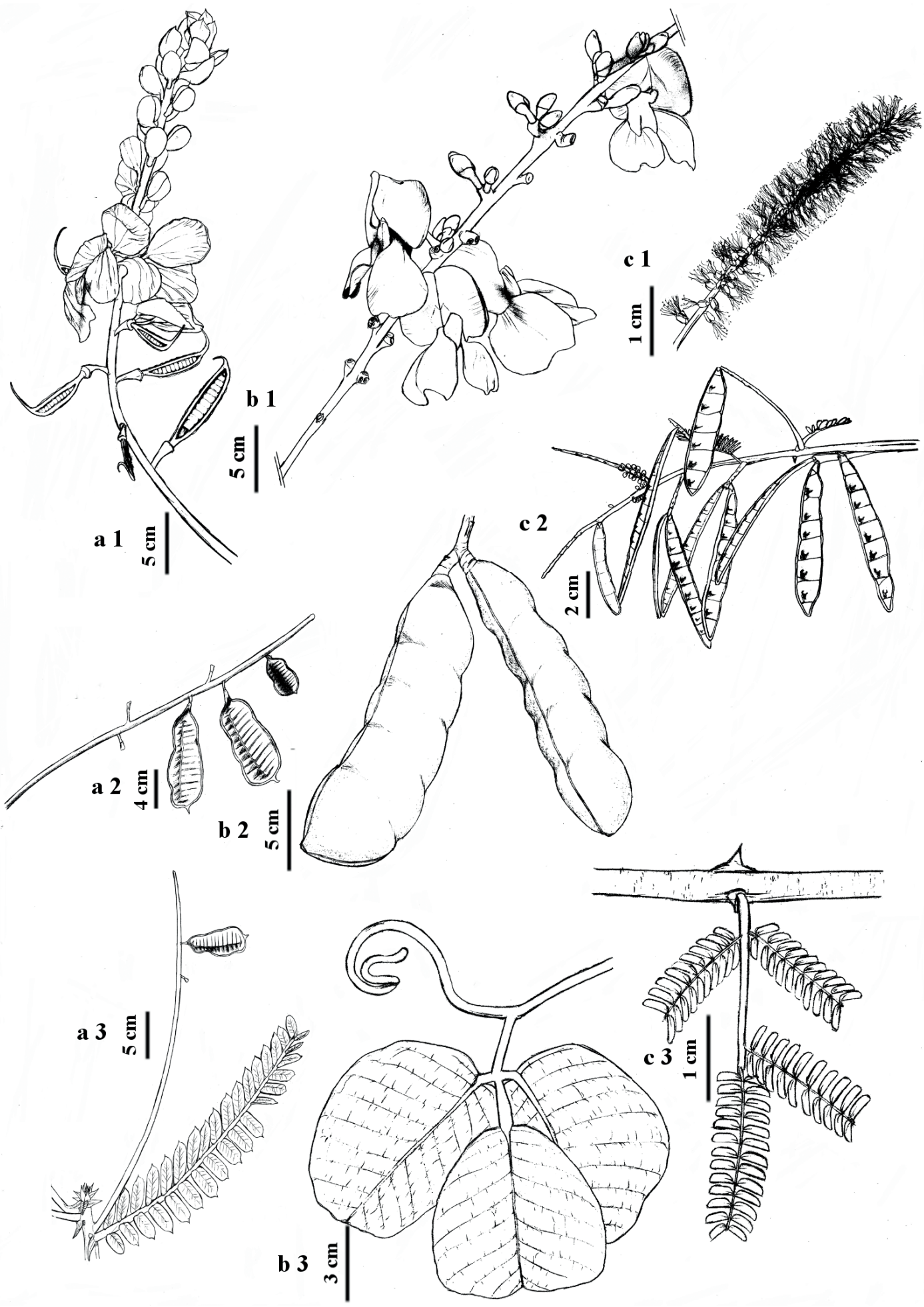

Figura 4. Representantes de Leguminosae obtidas na APA do Cariri, Paraíba, Brasil. a. Senna martiana (a1. Ramo reprodutivo. a2. Fruto. a3. Folha) (P.S.M. Ferreira 3 (ACAM)). b. Dioclea grandiflora (b1. Inflorescência. b2. Fruto. b3. Folha) (P.S.M. Ferreira 4 (ACAM)). c. Mimosa ophthalmocentra (c1. Inflorescência. c2. Ramo reprodutivo. c3. Folha) (P.S.M. Ferreira 5 (ACAM)). (Ilustrações: P.S.M. Ferreira).

Figure 4. Representatives of Leguminosae obtained at the APA do Cariri, Paraíba State, Brazil. a. Senna martiana (a1. Reproductive branch. a2. Fruit. a3. Leaf) (P.S.M. Ferreira 3 (ACAM)). b. Dioclea grandiflora (b1. Inflorescence. b2. Fruit. b3. Leaf) (P.S.M. Ferreira 4 (ACAM)). c. Mimosa ophthalmocentra (c1. Inflorescence. c2. Branch reproductive. c3. Leaf) (P.S.M. Ferreira 5 (ACAM)). (Illustrations: P.S.M. Ferreira). 
Os ramos prostrados, viscosos, constituem-se em importantes características para o reconhecimento de S. viscosa.

27. Vigna halophila (Piper) Maréchal, Mascherpa \& Stainier, Taxon 27(2/3): 202. 1978.

Figura $3 \mathrm{e}$

Material examinado: BRASIL. PARAíba: APA do Cariri, Boa Vista, Fazenda Salambaia, 07 $18^{\prime} 44,9^{\prime \prime}$, 36 $14{ }^{\prime} 40^{\prime \prime} \mathrm{W}, 400-600$ m, 5-VIII-2011, fl., fr., E.A. Lima 230 (ACAM).

Ocorre do Sul do México até o Norte da Argentina (também encontrada no Arquipélago de Comores), ocorrendo na Caatinga em ambientes perturbados e áreas inundáveis, de até 600 m (Queiroz 2009). Até então $V$. halophila era registrada apenas para o Estado da Bahia e neste trabalho, o Estado da Paraíba é acrescentado à área de distribuição da espécie.

Diferentemente das demais espécies de Papilionoideae de hábito trepador registradas na APA do Cariri, $V$. halophila não possui estandarte ressupinado.

28. Zornia echinocarpa (Moric.) Benth. in Mart., Fl. Bras. 15(1): 85. 1859.

Material examinado: BRASIL. Paraíba: APA do Cariri, Boa Vista, Fazenda Salambaia, 0 $7^{\circ} 12^{\prime} 10,3^{\prime \prime}$, $36^{\circ} 10^{\prime} 02,2^{\prime \prime} \mathrm{W}, 400-600 \mathrm{~m}, 11-\mathrm{II}-2011$, fl., fr., H.O. Machado-Filho 167 (ACAM).

Zornia echinocarpa é conhecida apenas do Nordeste do Brasil, onde ocorre em restinga e Caatinga sobre solo arenoso. Registrada apenas para o Estado da Bahia e inferida para Alagoas e Sergipe (Perez 2009, Queiroz 2009), constituindo neste trabalho um novo registro para o Estado da Paraíba.

Dentre as espécies do gênero Zornia encontradas na APA do Cariri, esta é facilmente reconhecível por ser a única a apresentar hábito arbustivo e tricomas equinados nos artículos do lomento.

29. Zornia latifolia Sm., Ress. Cycl. (Ress) 39: 4. 1819.

Material examinado: BRASIL. Paraíba: APA do Cariri, Boa Vista, Fazenda Salambaia, 07 $18^{\prime} 44,9^{\prime \prime} \mathrm{S}$, 36 14 '40"W, 400-600 m, 14-VIII-2010, fr., E.A. Lima 192 (ACAM).

Zornia latifolia tem ampla distribuição no Neotrópico, sendo comum em Cerrados, campos rupestres, beira de mata, mata de restinga e em praticamente todo o território brasileiro (Perez 2009, Queiroz 2009). Ocorrendo na Caatinga principalmente em áreas antropizadas, aparecendo logo após as chuvas, em elevações de até 600 m (Queiroz 2009).

Esta espécie pode ser diferenciada de Z. leptophylla, por apresentar folíolos elípticos a lanceolados e espigas de 7 a 13,5 cm de comprimento.

30. Zornia leptophylla (Benth.) Pittier, Bol. Soc. Venez. Cienc. Nat. 6: 196. 1940.

Material examinado: BRASIL. PARAíbA: APA do Cariri, Boa Vista, Fazenda Salambaia, $07^{\circ} 18^{\prime} 44,9^{\prime \prime}$, $36^{\circ} 14{ }^{\prime} 40^{\prime \prime} \mathrm{W}, 400-600$ m, 5-VIII-2011, fr., E.A. Lima 204 (ACAM).

Zornia leptophylla é uma espécie que pode ser encontrada em Minas Gerais e no Nordeste do Brasil (Perez 2009, Queiroz 2009). Segundo Mohlenbrock (1961), também é registrada para a Colômbia.

Distingue-se de Z. latifolia, com a qual é morfologicamente assemelhada, principalmente por apresentar folíolos ovais e espigas menores que $7 \mathrm{~cm}$ de comprimento.

31. Zornia myriadena Benth., Fl. Bras. 15(1A): 85 . 1859.

Material examinado: BRASIL. Paraíba: APA do Cariri, Boa Vista, Fazenda Salambaia, 07¹8'44,9"S, 36 ${ }^{\circ} 14 ' 40^{\prime \prime} \mathrm{W}, 400-600$ m, 20-VII-2010, fr., E.A. Lima 29 (ACAM).

Espécie com distribuição disjunta entre o Nordeste do Brasil, Cuba, Jamaica e Ilha de Santo Domingo (Haiti), ocorre frequentemente sobre afloramentos rochosos e solos arenosos (Perez 2009, Queiroz 2009). No Nordeste do Brasil, é comumente encontrada em áreas degradadas, em elevações de 250 a 900 m (Córdula et al. 2009, Queiroz 2009), sendo, nesse trablho, registrada pela primeira vez para a Flora do Estado da Paraíba.

Dentre as espécies herbáceas do gênero Zornia encontradas na APA do Cariri, Z. myriadena é a única que apresenta folhas 4-folioladas e lomento com mais de 8 artículos.

\section{Conclusão}

Papilionoideae mostrou-se a subfamília com maior riqueza na área de estudo, representada por nove gêneros, seguida de Caesalpinioideae, com seis gêneros, e Mimosoideae com três gêneros (tabela 1).

Dentre os gêneros registrados, o mais diversificado taxonomicamente foi Senna Mill. (Caesalpinioideae), 
com cinco espécies, seguido de Zornia J.F.Gmel. (Papilionoideae), com quatro, e os gêneros Bauhinia L. (Caesalpinioideae), Chamaecrista Moench. (Caesalpinioideae), Dioclea Kunth (Papilionoideae), Indigofera L.(Papilionoideae), Mimosa L. (Mimosoideae) e Poincianella Britton \& Rose (Caesalpinioideae), com duas espécies cada um (tabela 1 ).

O hábito arbustivo foi o mais representativo, com $45,2 \%$ do total de espécies registradas, o que entra em consonância com a fitofisionomia de Caatinga inferida para a área segundo Andrade-Lima (1981), seguido pelo hábito herbáceo e o arbóreo com 22,6 e $16,1 \%$ respectivamente. As trepadeiras e lianas perfizeram respectivamente 9,7 e $6,5 \%$ das espécies. Foram encontradas sete espécies mencionadas como endêmicas do ecossistema Caatinga $(C$. belemii var. belemii, D. grandiflora, I. blanchetiana, $P$. gardneriana, P. microphilla, $P$. stipulacea e $S$. martiana), constituindo $22,6 \%$ das 31 espécies registradas na APA. Adicionalmente, os sete novos registros para o estado da Paraíba detectados na área (C. belemii var. belemii, D. violacea, I. blanchetiana, P. microphilla, V. halophila, Z. echinocarpa e Z. myriadena), confirmam a expressiva riqueza florística associada à microrregião do Cariri paraibano, especialmente para a família Leguminosae.

\section{Agradecimentos}

$\mathrm{O}$ primeiro Autor agradece à Universidade Estadual da Paraíba (UEPB) pela concessão de bolsa de Iniciação Científica (IC); a Elimar Alves de Lima e Hermes de Oliveira Machado-Filho pela obtenção de amostras de espécies de Leguminosae na APA do Cariri. J.I.M. Melo agradece ao CNPq (Conselho Nacional de Desenvolvimento Científico e Tecnológico), pelo financiamento do projeto "Flora Vascular de Ambientes Rochosos no Semiárido Paraibano - Nordeste do Brasil: Diversidade, Distribuição e Conservação" (Proc. no 562146/2010-5) e a concessão de bolsa de Produtividade em Pesquisa (Proc. no ${ }^{-302751 / 2012-}$ 2); à Pró-Reitoria de Pós-Graduação e Pesquisa da Universidade Estadual da Paraíba (PRPGP/UEPB) pela concessão de auxílio financeiro ao projeto "Flora Vascular da APA do Cariri, Paraíba, Nordeste do Brasil" (PROPESQ - Programa de Incentivo à Pós-Graduação e Pesquisa - Proc. no 057/2011).

\section{Literatura citada}

Abílio, F.J.P. 2010. Bioma caatinga: ecologia, biodiversidade, educação ambiental e práticas pedagógicas. Editora Universitária da UFPB, João Pessoa, pp. 13-55.
Alves, J.J.A. 2007. Geoecologia da semi-árido do Nordeste brasileiro. CLIMEP: Climatologia e Estudos da Paisagem 2: 58-71.

Alves, J.J.A. 2009. Caatinga do Cariri Paraibano. Geonomos 17: 19-25.

Andrade-Lima, D. 1981. The caatingas dominium. Revista Brasileira de Botânica 4: 149-153.

APG III. 2009. An update of the Angiosperm Phylogeny Group classification for the orders and families of flowering plants. Botanical Journal of the Linnean Society 161: 105-121.

Ariati, S.N., Murphy, D.J., Udovicic, F. \& Ladiges, P.Y. 2006. Molecular phylogeny of three groups of acacias (Acacia subgenus Phyllodineae) in arid Australia based on the internal and external transcribed spacer regions of nrDNA. Systematics and Biodiversity 4: 417-426.

Barbosa, M.R.V., Agra, M.F., Lima, R.B. \& Cunha, J.P. 2003. Biodiversidade na Caatinga Paraibana. In: M.N.C. Bastos \& J.U.M. Silva (eds.). Desafios da Botânica brasileira no novo milênio: inventário, sistematização e conservação da diversidade vegetal. Museu Paraense Emilio Goeldi (MPEG), Universidade Federal Rural da Amazônia (UFRA), Embrapa, Belém, pp. 91-92.

Barbosa, M.R.V., Lima, J.R., Cunha, J.P., Agra, M.F. \& Thomas, W.W. 2007. Vegetação e flora no Cariri Paraibano. Oecologia Brasiliensis 11: 313-322.

Barbosa-Fevereiro, V.P. 1977. Centrosema (A.P. Candolle) Bentham do Brasil-Leguminosae- Faboideae. Rodriguésia 29: 159-219.

Barneby, R.C. 1991. Sensitivae Censitae, a description of the genus Mimosa L. (Mimosaceae) in the New World. Memoirs of the New York Botanical Garden 65: 1-835.

Bernardes, N. 1999. As Caatingas. Estudos Avançados 13: 69-78.

Camargo, R.A. \& Miotto, S.T.S. 2004. O gênero Chamaecrista Moench (Leguminosae-Caesalpinioideae) no Rio Grande do Sul. Iheringia, Série Botânica, 59: 131-148.

Cardoso, D.B.O.S. \& Queiroz, L.P. 2007. Diversidade de Leguminosae nas caatingas de Tucano, Bahia: Implicações para a fitogeografia do Semi-Árido do Nordeste do Brasil. Rodriguésia 58: 379-391.

Cohen, M. \& Duqué, G. 2001. Le deux visages du Sertão: Stratégies paysannes face aux sécheresses (Nordeste du Brésil). Éditions de L'IRD, Paris.

Córdula, E., Queiroz, L.P. \& Alves, M. 2009. Leguminosae. In: M. Alves, M.F. Araújo, J.R. Maciel \& S. Martins (orgs.). Flora de Mirandiba. Associação Plantas do Nordeste, Recife, pp. 183-235.

Cortez, J.S.A, Cortez, P.H.M., Franco, J.M.V. \& Uzunian, A. 2007. Caatinga. Harbra, São Paulo.

Eisinger, S.M. 1987. O gênero Indigofera L. (LeguminosaePapilionoideae- Indigofereae) no Rio Grande do Sul. Acta Botanica Brasilica 1: 123-140. 
Fialho, D.A., Araújo, S.M.S. \& Bagnoli, E. 2010. Diagnóstico geoambiental e geoturístico na Área de Proteção Ambiental do Cariri Paraibano. XVI Encontro Nacional dos Geógrafos, Porto Alegre, pp. 1-10.

Fortuna-Perez, A.P. 2009. O gênero Zornia J.F. Gmel. (Leguminosae, Papilionideae, Dalbergieae): revisão taxonômica das espécies ocorrentes no Brasil e filogenia. Tese de Doutorado, Universidade Estadual de Campinas, Campinas.

Goedert, W.J., Wagner, E. \& Barcellos, A.O. 2008. Savanas Tropicais: dimensão, histórico e perspectivas. In: F.G. Faleiro \& A.L.F. Neto (eds.). Savanas: desafios e estratégias para o equilíbrio entre sociedade, agronegócio e recursos naturais. Planaltina: Embrapa Cerrados, pp. 49-80.

Gurevitch, J., Scheiner, S. \& Fox, G.A. Tradução: Becker, F.G., Duarte, L.S., Dillenburg, L.R., Oliveira, P.L., Müller, S.C., \& Hartz, S.M. Ecologia Vegetal. 2. ed. Artmed, Porto Alegre.

Irwin, H.S. \& Barneby, R.C. 1982. The American Cassiinae. A synoptical revision of Leguminosae tribe Cassieae subtribe Cassiinae in the New World. Memoirs of the New York Botanical Garden 35: 1-918.

Lacerda, A.V., Barbosa, F.M. \& Barbosa, M.R.V. 2007. Estudo do componente Arbustivo-arbóreo de matas ciliares na bacia do Rio Taperoá, semi-árido paraibano: Uma perspectiva para a sustentabilidade dos recursos naturais. Oecologia Brasiliensis 11: 331-340.

Lee, Y.-T. \& Langenhein, J.H. 1975. Systemetics of the genus Hymenaea L. (Leg. Caesalpinioideae, Detarieae). University California Publication Botany 69: 1-109.

Lewis, G.P. 1987. Legumes of Bahia. Royal Botanic Gardens Kew, Surrey.

Lewis, G.P. 2014. Poincianella. In: Lista de Espécies da Flora do Brasil. Jardim Botânico do Rio de Janeiro. Disponível em http://floradobrasil.jbrj.gov.br/2012/ FB109775 (acesso em 06-I-2014).

Lievens, A.W. 1992. Taxonomic treatment of Indigofera L. (Fabaceae: Faboideae) in the New World. PhD thesis, Lousiana State University.

Lima, E.A. \& Melo, J.I.M. 2015. Biological spectrum and dispersal syndromes in an area of semi-arid region of north-eastern Brazil. Acta Scientiarum, Biological Sciences, 37: 91-100.

Lima, H.C., Queiroz, L.P., Morim, M.P., Dutra, V.F., Bortoluzzi, R.L.C., Iganci, J.R.V., Fortunato, R.H., Vaz, A.M.S.F., Souza, E.R., Filardi, F.L.R., Garcia, F.C.P., Fernandes, J.M., Martins-da-Silva, R.C.V., Perez, A.P.F., Mansano, V.F., Miotto, S.T.S., Lima, L.C.P., Oliveira, M.L.A.A., Flores, A.S., Torke, B.M., Pinto, R.B., Lewis, G.P., Barros, M.J.F., Schütz, R., Pennington, T., Klitgaard, B.B., Rando, J.G., Scalon, V.R., Costa, L.C., Silva, M.J., Moura, T.M., Barros, L.A.V., Silva, M.C.R., Queiroz, R.T., Sartori, A.L.B., Camargo, R.A., Lima, I.B., Costa, J., Soares, M.V.B., Snak, C., Valls, J.F.M., São-Mateus, W., Falcão, M.J., Cardoso, D.B.O.S., Tozzi, A.M.G.A., Martins, V.C., Souza, V.C., Meireles, J.E. \& Reis, I.P. 2015. Fabaceae. In: Lista de Espécies da Flora do Brasil. Jardim Botânico do Rio de Janeiro, Rio de Janeiro. Disponível em http://floradobrasil.jbrj.gov.br/2012/ FB000115 (acesso em 05-I-2015).
LPWG (The Legume Phylogeny Working Group). 2013. Legume phylogeny and classification in the $21^{\text {st }}$ century: Progress, prospects and lessons for other species-rich clades. Taxon 62: 217-248.

Machado-Filho, H.O. 2011. Estudo florístico de um ambiente rochoso da Área de Proteção Ambiental (APA) do Cariri, Paraíba: Riqueza, Similaridade e Fitogeografia. Dissertação de Mestrado. Universidade Estadual da Paraíba, Campina Grande.

Mohlenbrock, R.H. 1961. A monograph of the leguminous genus Zornia. Webbia 16: 1-141.

Morim, M.P. 2014. Piptadenia. In: Lista de Espécies da Flora do Brasil. Jardim Botânico do Rio de Janeiro. Disponível em http://reflora.jbrj.gov.br/jabot/ floradobrasil/FB83593. (acesso em 07-VI-2014).

Ortolani, F.A., Melloni, M.N.G., Mariotto, C.F.G. \& Moro, J.R. 2010. Caracterização citogenética em Anadenanthera colubrina (Vell.) Brenan (Mimosoideae) e Guazuma ulmifolia Lam. (Sterculiaceae). Acta Botanica Brasilica 24: 299-303.

Prado, D.E. \& Gibbs, P.E. 1993. Patterns of species distributions in the dry seasonal forest of South America. Annals of the Missouri Botanical Garden 80: 902-927.

Queiroz, L.P. 2009. Leguminosas da Caatinga. Universidade Estadual de Feira de Santana/Royal Botanic Gardens, Kew/Associação Plantas do Nordeste, Feira de Santana.

Queiroz, L.P. 2006. The Brazilian caatinga: Phytogeographical patterns inferred from distribution data of the Leguminosae. In: R.T. Pennington, G.P. Lewis \& J.A. Ratter (eds.). Neotropical caatingas and dry forests: Plant diversity, biogeography, and conservation. Taylor \& Francis CRCPress, Boca Raton.

Queiroz, L.P. 2014. Canavalia. In: Lista de Espécies da Flora do Brasil. Jardim Botânico do Rio de Janeiro. http://reflora.jbrj.gov.br/jabot/floradobrasil/FB22855. (acesso em 07-VI-2014).

Queiroz, L.P. 2014. Dioclea. In: Lista de Espécies da Flora do Brasil. Jardim Botânico do Rio de Janeiro. Disponível em http://reflora.jbrj.gov.br/jabot/floradobrasil/FB29620. (acesso em 07-VI-2014).

Queiroz, L.P., Rapini, A. \& Giulietti, A.M. (orgs.). 2006. Towards greater knowledge of the Brazilian Semiarid biodiversity. Ministério da Ciência e Tecnologia, Brasília.

Radford, A.E., Dickison, W.C., Massey, J.R. \& Bell, C.R. 1974. Vascular Plant Systematics. Harper Collins, New York.

Silva, L.L.S., Lima, E.O., Nascimento, S.C., Mota, D.L., Silva, N.H., Almeida, E.R. \& Silva, M.G.S. 2010. Avaliação da atividade antimicrobiana de extratos de Dioclea grandiflora Mart. ex Benth., Fabaceae. Revista Brasileira de Farmacognosia 20: 208-214. 
Simoni, F., Pitelli, R.L.C.M. \& Pitelli, R.A. 2005. Efeito da incorporação no solo de sementes de fedegoso (Senna obtusifolia) colonizadas por Alternaria cassiae no controle desta planta infestante. Summa Phytopathologica 32: 367-372.

Simpson, M.G. 2006. Plant Systematics. Elsevier Incorporation, Oxford.

Souza, V.C. \& Bortoluzzi, R.L.C. 2014. Senna. In: Lista de Espécies da Flora do Brasil. Jardim Botânico do Rio de Janeiro. Disponível em http://floradobrasil.jbrj.gov. br/2012/FB028201 (acesso em 06-I-2014).
Souza, V.C. \& Bortoluzzi, R.L.C. 2014. Chamaecrista.In: Lista de Espécies da Flora do Brasil. Jardim Botânico do Rio de Janeiro. Disponível em http://floradobrasil.jbrj. gov.br/2012/FB018302 (acesso em 06-I-2014).

Vaz, A.M.S.F. 2014. Bauhinia. In: Lista de Espécies da Flora do Brasil. Jardim Botânico do Rio de Janeiro. Disponível em http://floradobrasil.jbrj.gov.br/2012/ FB082659 (acesso em 06-I-2014).

Vaz, A.M.S.F. \& Tozzi, A.M.G.A. 2003. Bauhinia ser. Cansenia (Leguminosae: Caesalpinioideae) no Brasil. Rodriguésia 54: 55-143. 